\title{
Gender Differences in Learning English as a Second Language among Primary Students in Brunei
}

\section{Darussalam}

\author{
Malai Zeiti Sheikh Abdul Hamid \\ Centre for Communication Teaching and Learning, Universiti Teknologi Brunei, \\ Jalan Tungku Link, Mukim Gadong, BE2410, Bandar Seri Begawan, Brunei Darussalam \\ Tel: 673-2-2461020_E-mail: zeiti.hamid@utb.edu.bn
}

Received: April 8, 2017 Accepted: April 15, 2020 Published: April 20, 2020

doi:10.5296/ijele.v8i2.16882 URL: https://doi.org/10.5296/ijele.v8i2.16882

\begin{abstract}
English is a major medium for learning in the Bruneian school system and is an important feature of Brunei's bilingual education policy. There is a concern that students in Brunei have low literacy levels and experience language difficulties in the classroom. Bruneian students, who are second language learners of English encounter problems in communicating in the language due to lack of input at home and the school environment. Through qualitative interviews with young children, gender differences were found in language learning as early as the primary schools. Girls were keen to participate in activities which increased their literacy skills than boys.
\end{abstract}

Keywords: low literacy, bilingual policy, gender differences, second language learners, primary students, codeswitching, communication 


\section{Introduction}

This paper will present data obtained from a particular cultural context, Brunei - a small state located on the island of Borneo. Brunei, a former British Protectorate, gained her sovereignty and independence in 1984. However, Britain has left much of its influence in Brunei, in terms of the nation's legal, administrative and public services, particularly in education. For the past twenty years, much of Brunei's system of education including the public school examinations has been derived from the British system. In 1985, Brunei adopted a dwibahasa (dual language) or bilingual education policy. With its implementation, all government schools followed a single system with a common national curriculum from pre-school to pre-university. The policy seeks to provide a minimum of 12 years of education for all citizens: 7 years in pre-school and primary education, 3 years in lower secondary and 2 years in upper secondary or vocational/technical education (The Government of Brunei, 1985).

Accordingly, two main languages, first, Standard Malay (also known as the Malay Language) and second, English are used as the medium of instruction in primary and secondary schools. English as plays the role as the second language in Brunei. Often, in multilingual countries, many children grow up with the ability to speak more than one language. Having more than one language and literacy is most common in countries that operate multilingualy (Datta, 2000). Brunei is an example in which the majority of Bruneian children are exposed to a variety of languages (and dialects) at home and school. With the bilingual system, the two major languages are used in school, which begins as early as early primary education. Children in Brunei thus use a variety of other languages at home and school, which includes Brunei Malay (which is the home language or mother tongue), Standard Malay (the national language in school), the English Language (the second language in school) and the Arabic Language (the language for religious education).

\subsection{Brunei’s Bilingual Education Policy}

Brunei, as whole, practices a form of additive bilingualism. Garcia (2009) explains how 'bilingualism for prestigious groups and the elite has always been additive, a model under which the second language is added to the person's repertoire and the two languages are maintained' (Garcia, 2007:51).

Cummins (1988) asserts that opportunities to use languages for genuine communication are important for successful bilingual programmes. In Brunei's bilingual education system, the two main languages, Standard Malay (hereafter known as Malay) and English appear to have distinct roles in the school system. English is the language for learning content based subjects such as Mathematics and Science at the upper primary level, for children from ages 9 to 13 years old, while other subjects are usually taught in Malay (see Table 1).

In formal schooling, there is a high expectation to produce Brunei children who are able to speak, read and write fluently in the two languages. While Malay is the medium for teaching majority of school subjects (excluding English Language) in the lower primary, pupils need to be proficient in the second language to cope with the switchover at upper primary level.

In subsequent years, changes in the school curriculum in Brunei have focused on developing 
human resources by increasing skills and capabilities in science and technology. In 1992, for example, Science was upgraded to the status of a subject on its own in upper primary and it also became a compulsory subject at secondary education.

Table 1. Compulsory subjects in primary and secondary schools in the existing education system for Brunei (from 1985-2008)

\begin{tabular}{|l|l|}
\hline English Medium & Malay Medium \\
\hline Lower Primary & (age 5-8 years) \\
Malay Language \\
Mathematics \\
General Studies (History, Science, Geography) \\
& Islamic Religious Knowledge \\
& Physical Education \\
& Arts and Handicrafts \\
& Civics \\
\hline Upper Primary & (age 9-11 years) \\
English Language & Malay Language \\
Mathematics & Islamic Religious Knowledge \\
History & Physical Education \\
Science & Arts and Handicrafts \\
Geography & Civics \\
\hline & \\
Lower Secondary & (age 12-14 years) \\
English Language & Malay Language \\
Mathematics & Islamic Religious Knowledge \\
History & \\
Science & \\
Geography & \\
\hline Upper Secondary & (age 15-16 years) \\
English Language & Malay Language \\
Sathematics & \\
\hline
\end{tabular}

The brief account of the bilingual education provides some background of the distinct roles played by the two languages in Brunei's school system- one is a local vernacular which is widely spoken and used by majority of the people. The other is still considered as a foreign language, despite being introduced as a second language in the bilingual policy and is least popular among the locals. To a certain extent, the reinforcement of the bilingual policy will impact the lives of the Brunei children and their perceptions of the languages upon leaving school. In particular, the rate of the success of the use of the English language has been much 
debated in the local media over the past decade.

\subsection{Current Status of English Language in Primary and Secondary Schools}

Studies have revealed that Bruneian children tend to have limited contact with English at home and in school (Larking, 1996; Larking and Ahmad, 1997; Ghadessy and Nicol, 2002; Jones, 2003 and Arthur and Martin, 2006). Larking and Ahmad (1997), for example, in their study, found that Malay was the dominant language in the home and no attempt was made by Bruneian parents to speak English with their children. In school, they found that minimal attention was given to oral language proficiency in English as teaching concentrated on monthly tests and textbook exercises. English is also not widely practiced particularly among students in Brunei government schools.

A prominent feature in the teaching of Brunei primary classrooms is code switching (Jones, Martin and Ozog, 1993; Beardsmore, 1998; Jones, 2003; Martin, 1996, 1998, 1999, 2005; Arthur and Martin, 2006 and Garcia, 2009). Arthur and Martin (2006) also point out that the model of teaching and learning in English lessons in Brunei is that of behaviourism rather than a communicative one. While teachers tend to code switch in the primary classrooms, their pupils turn to memorisation and rote learning. Larking and Ahmad (1997) also assert that the teaching of English in Brunei revolves around the use of textbooks and monthly tests, with little attention on oral language development. They propose some reasons for student failure to acquire competence in English: lack of practice in speaking English, lack of reading outside of classroom, lack of reading practice leading to reluctant writers; and lack of motivation to learn.

At the secondary level, Dhindsa (2008) proposes that Brunei students fail to express their personal views in the classroom, which he believes could be in part due to their low proficiency in English. In addition, he states how Brunei students have inadequate input in English at home. It can thus be inferred that Brunei students may not be confident in expressing themselves in English due to the lack of communicative practices and the lack of English input at the school and home environment.

In general, students in Brunei appeared to have a choice of being taught to learn difficult monolingual English texts in Malay through code switching. In this view, there is thus very little need and motivation for teachers to use English for teaching content based subjects when they can resort to use their first language.

\section{Related Studies on Literacy}

Literacy is increasingly viewed as a social practice which is evident thorough numerous influential publications in Anglophone countries, such the UK and USA. Literacy in these countries are perceived as a reflection of the situations in our everyday lives. A well-known example of an ethnographic study of everyday literacy practices is presented in the work of Barton, Hamilton and Ivanic (2000). In a literate society such as western Anglophone countries, children often find themselves in favourable environments surrounded by print and 
textual images. As they grow older, children begin to show interest in writing through their observations of other people writing and through opportunities in literacy practices, such as writing shopping lists and listening to bedtime stories (Barton, 2007; Purcell-Gates, 1996, Heath, 1982).

There has also been considerable effort by studies that investigates the level of competency of children as literacy learners and how best to define conditions which make them as 'literate'. From a socio-cultural perspective, literacy involves more than reading and writing and this distinction can be blurred by rapid developments in the mass media and computers. Langer (1987:4) explains how 'a focus on simple reading and writing skills as defining "literate" thinkers, and on uses of oral and written language as involving different intellectual dimensions, are unhelpful distinctions. Langer (1987) continues to describe how writing and reading skills must include knowledge of the social practices underpinning the contexts in which the use of the target language occurs and suit the purposes, needs and uses of literacy which may vary between individuals and within communities.

Language and culture are inter-related. When children make sense of their lives, they are inadvertently trying to making sense of their environment and their language experience through shared cultural activities. Children's spoken and literary experiences form an important part of their culture. These experiences are even more profound among bilingual children who are perceived to be living in two separate 'cultures', each relatively separate from one another (Kenner, 2003). In other words, when children are being exposed to two or more languages, they not only have the benefit of learning to speak or use various languages, they also likely to learn the cultural values and traditions which come with the languages.

For many bilingual children, in their everyday experiences they are constantly interacting with various languages (or varieties) in both spoken and written discourse at homes, at school and within their communities. This situation is true of the children in Brunei. For the Bruneian children, their language and everyday experiences are largely done in their home language, Brunei Malay. In school, they face encounters with formal languages such as Malay, English and Arabic. More importantly, it is noted that pupils generally appear to lack adequate proficiency in English to help them get through the school years. The trend in low standards in English (which implies low literacy) seemed to continue until pupils reach secondary education. This can be observed in the examination results of students in government schools who are unable to achieve credit passes in the English Language at G.C.E Cambridge 'O’ Level.

The language situation in Brunei thus reflects a bilingual education system which aspires to achieving successes in raising standards in English. However, there may be broader cultural issues which need to be addressed before these successes can be achieved. One possible explanation is the interplay of several languages at any one time which could lead to various language difficulties and low literacy levels. 


\section{NI Macrothink}

\section{Methodology}

A qualitative method was chosen to collect data due to the nature of the study which focused on the lives of young children in Brunei. This method had the advantage of giving a rich and 'thick' description of human experiences due to its exploratory nature (Geertz, 1993). Interviews were conducted to investigate the impact of the English Language and levels of literacy as a consequence of Brunei's bilingual education system. The data in this study came from students who have had three years of learning English in lower primary education.

Individual interviews were carried among students from 4 different primary schools in Brunei. Two schools were located in urban parts of Brunei, while the other two schools were located in semi-rural areas. 15 participants were interviewed: 8 girls and 7 boys. Each interview took place in a suitable quiet room in each respective schools. The interview lasted from twenty to thirty minutes per student. As the interviewees were young children who recently started to use English in Year 4, the language used to conduct interview questions had to be made easier to generate responses.

There were 26 proposed interview questions posed:

Q. 1) What is your hobby? In your spare time?

Q. 2) What are your favourite TV programmes?

Q. 3) Do you feel afraid to speak to me in English? Why? Why not?

Q. 4) Is it easy for you to speak English? Why? Why not?

Q. 5) If you speak English, who do you speak to?

Q. 6) Do you like listening to English music or songs?

Q. 7) Do you like reading?

Q. 8) Why do you like reading?

Q.9) What is your favourite book?

Q.10) Do your parents read books, magazines or newspapers?

Q.11) What books, magazines or newspapers do your parents read?

Q.12) Do you like writing?

Q.13) Why do you like writing?

Q.14) Do you like composition?

Q.15) What do you write?

Q.16) Do you have a diary?

Q.17) Do you like drawing?

Q.18) Have you ever written or made birthday cards?

Q.19) What things do you write in the card?

Q.20) Have you ever written shopping lists?

Q.21) Have you ever written letters?

Q.22) Do you have a computer or laptop at home?

Q.23) What is the computer or laptop used for?

Q.24) What kinds of games do you play?

Q.25) Does anyone teach you at home?

Q.26) What do they (your parents) teach you? 


\section{Macrothink \\ International Journal of English Language Education \\ ISSN 2325-0887 \\ 2020, Vol. 8, No. 2}

\section{Qualitative Analysis and Results}

This section describes the analysis and data interpretation of the student interviews conducted in the Brunei primary schools. A considerable amount of direct quotation from the student interviews were used to generate data. No particular method of analysis had been used to analyse the students' responses as they gave only very short responses. For example, in the question, 'Do you like reading?', students' responses were: 'Yes', 'No'. For another question, 'If you speak English, who do you speak to?', their responses were: 'Sometimes I speak to my sister English', 'Sometimes my mother'.

The interview questions were grouped into 6 categories which cover background, motivation, speaking/listening, reading, writing and home literacy. For the purpose of the analysis, it was convenient to use gender differences as a means for making sense of the data. Firstly, there were nearly an almost equal amount of boys and girls who were involved in the interviews. Thus, a comparison in terms of the responses between both genders were easily seen. Secondly, due to the minimum responses given by the participants, there were no other adequate patterns found that could be used to analyse the data apart from gender differences.

The question and categories for the interviews are as follows:

i) the students' personal hobbies/likes (background) ('Q.1 What is your hobby? In your spare time?' and 'Q.2 What is your favourite TV programmes?')

ii) the students' feelings about English (motivation) ('Q.3 Do you feel afraid to speak to me in English? Why? Why not?' and 'Q.4 Is it easy for you to speak English? Why? Why not?')

iii) the students' feelings about speaking English (speaking/listening) ('Q.5 If you speak English, who do you speak to?' and 'Q.6 Do you like listening to English music or songs?')

iv) the students' feelings about reading, and what they read (reading) ('Q.7 Do you like reading?', 'Q.8 Why do you like reading?', 'Q.9 What is your favourite book?', 'Q.10 Do your parents read books, magazines or newspapers?' and 'Q.11 What books, magazines or newspapers do your parents read?')

v) the students' feelings about writing, and what they write (writing) ('Q.12 Do you like writing?', 'Q.13 Why do you like writing?', 'Q.14 Do you like composition?', Q.15 What do you write?', 'Q.16 Do you have a diary?' and 'Q.17 Do you like drawing?'.

vi) the students' home literacy and literacy practices ('Q.18 Have you ever written 
or made or birthday cards?', 'Q.19 What things do you write in the card?', 'Q.20 Have you ever written shopping lists?', 'Q.23 What is the computer used for?', 'Q.24 What kinds of games do you play?', 'Q.25 Does anyone teach you at home?' and 'Q.26 What do they (your parents) teach you?').

ii) Some examples of the students' responses for the interview questions which discusses the students' feelings about English (motivation) were as follows:

\section{Brief:}

There were 2 questions related to feelings about English: 'Q. 3) Do you feel afraid to speak to me in English? Why? Why not?' and 'Q. 4) Is it easy for you to speak English? Why? Why not?'

'Q.3 Do you feel afraid to speak to me in English?' :

'No': (G- G92), (G- Nu42), (G- Ns65), (B- I40), (B- N232), (B- Hf33),

'Yes': (G- A46), (G- Aq163), (B- Fq28),

'I think so' (G- S43)

\section{'Q.3 Why? Why not? (Fear of speaking English') :}

'I'm so afraid' (G- A52)

'Because if I didn't talk in English with my mother, my mother will be serious (sic)' (GNs67)

'Don't understand' (G- Aq168)

'Nervous, afraid, but sometimes afraid, but sometimes I don't' (B- N38)

'Because I'm student English' (B- Hf35)

'Because I always speaking English, sometimes (sic)' (B- N234)

'Q. 4 Is it easy for you to speak English? :

'Um I don't know' (G- S27)

'Yes, I feel easy', (G- A28), (G- Aq30),

'Yes': (B- Hf23), (B- Fz41),

'A little bit hard, it's hard a little' (G- G26),

'Ennn .. No. Yes.' (G- Nu22)

'No' : (B-I34), (B - Fq36)

'Sometimes': (B- F29)

'Q.4 Why? Why not? (Ease in speaking English)' :

'The English is so fun' (sic) (G- A28)

'Because it's fun' (G- A30), (B- Fz43), (B- Fq26)

'It's easy because I learn from my teacher' (G- A36)

'Because I can speak English to my friend, my mother and my father' (B-Hf25)

'Because I always speaking in English, and sometimes and always' (sic) (B-N23) 
Analysis:

In terms of fear in speaking English (Q. 3), 6 students disagreed (3 girls 3 boys), 3 students agreed ( 2 girls, 1 boy) and 1 girl answered 'I think so'. 3 boys and 2 girls (S1, S2, S3, $\mathrm{S} 12, \mathrm{~S} 13)$ did not respond. While girls gave their reasons for their fears, such as 'I'm so afraid', 'Don't understand' and 'my mother will serious', while the boys relayed different comments, such as 'Nervous, afraid, but sometimes afraid, but sometimes I don't', 'Because I'm student English' (sic) and 'Because I always speaking English, sometimes (sic)'. Referring to speaking English, 4 students answered 'Yes' (2 boys, 2 girls). 2 boys answered 'no'; 2 girls replied 'I don't know', 1 girl replied 'a little bit hard' and 1 boy said 'sometimes'. No responses were given by 4 girls and 3 boys (S2, S3, S4, S10, S11, S13 and S14). Both genders expressed that English is fun ( 2 boys, 2 girls). 1 boy expressed how he always spoke in English, while another boy stated he spoke English to his family. 1 girl stated how she felt it was easy to speak English by learning from her teacher.

Overall, there were almost an equal number of boys and girls who share the same fears about speaking in English. No observable gender differences have been found with these interview questions. It is possible that students may have a lot of fears in speaking in English but feel afraid to admit their own fears.

The general results of the qualitative data are summarised below:

In terms of background, the analysis revealed one gender difference. In their spare time, the girls in the study preferred to sing, to colour, to draw, to use the computer, to complete their homework, to watch TV and to play piano. Boys, on the other hand, preferred to play video games and football. It was interesting to find that the girls are watching more TV than the boys. The types of TV programmes also differed between the two genders. Girls enjoyed watching children's programme such as Disney, musical programmes (High School Musical 1 $\&$ 2), and children's TV programme (Bratz, Powerpuff Girls). Boys have a preference for adventure/sport TV programmes such as Ben 10, Transformers, Slam Dunk and Super Sport (which can be assumed to be aired in English).

In the next category, motivation, there was very little evidence to support any gender differences in terms of students' feelings about English. Both genders expressed they have some fears in speaking English, particularly the girls. The boys, on the other hand, seemed less apprehensive about English. There were few responses given by students with the interview question in this category. However, from those who responded, the girls tended to give neutral or negative responses.

In terms of speaking/listening, the analysis revealed that each gender spoke English to a different group of people. The girls spoke English with their sisters, parents and friends, while boys spoke English with their sister, friends and teachers. The boys, however, did not mention speaking in English with their parents. In terms of listening, the boys appeared to enjoy listening to English music/songs while the girls do not. When the girls do listen to English music/songs, they preferred music/songs from popular TV programmes such as Hanna Montana and High School Musical. Boys, on the other hand, have a liking for popular 
English songs such as 'Beautiful Girls' (3 votes), 'Linkin Park' and 'Smack That'. This could indicate that both genders are affected by different kind of influences.

From the reading category, it was found that both genders enjoy reading. The most popular reason for liking reading was because reading was fun. There was a gender difference in terms of the students' reading genre. The boys enjoyed reading comics, while the girls preferred fairytales and children's stories. This is a trend that appears to mirror studies conducted in western, Anglophone countries such as the UK. In terms of the students' parental background, there was no clear gender difference. Both sexes revealed that female parents read (Malay) women's magazine, while male parents read largely Malay newspapers.

In writing, one very significant gender difference was found. From those who responded, it was found that the girls seemed to enjoy writing more than the boys. In terms of reasons for liking writing, no comments came from the boys. It could be inferred that the girls may have more positive attitudes towards writing than the boys. This was shown by the girls who described writing as fun/funny and that writing taught them new words. Still, the responses showed that both genders have little enthusiasm for writing.

From those responded, the girls stated they wrote stories that concern personal things, such as their friends, family and composition. Boys, however, have a preference for writing about themselves. Another interview question investigated how many students kept a diary. Only 5 students ( 3 boys and 2 girls) out of 15 students owned a diary. There were no clear gender differences with this question. In relation to drawing, the girls preferred to draw natural things such as flowers, butterflies and pictures depicted from children's stories and fairytales (such as Cinderella and Ariel). Boys, on the other hand, drew cars and action figures such as superheroes and cartoons.

In terms of home literacy, it was found that less than half of the students in the study (3 boys and 3 girls) agreed they were taught by their family. Those who responded mentioned their family members were taught by close relatives (father, mother, sister and uncle). The results showed that more girls tend to have home teaching by a family member in comparison to the boys (responses from 7 girls, 5 boys). In terms of the types of home teaching received, the students named a few school subjects being taught: English, Religious Knowledge, Malay, Maths, Science and Geography.

In terms of literacy practices, very few responses were given. Some gender differences were found. Girls seemed to have had more experience in writing/making birthday cards. The girls also seemed more expressive and showed their emotions and feelings in the cards they wrote, such as 'Happy Birthday', 'I'm sorry' and 'I love you're. No illustrations came from the boys in terms of what they wrote in the cards. With shopping lists and letters, there were too little responses from the students, so there not sufficient evidence to support gender differences. Half of the students ( 3 boys and 4 girls) owned a computer/laptop at home. Girls gave reasons for using the computer for playing games, chatting and learning for school subjects ( 5 responses). The boys too used the computer for playing games, to write letters and for putting songs into the IPod (5 responses). In terms of types of computer games played, no clear gender differences were found. Both genders mentioned a range of games played such as 
Sims, baking, puzzles, Zuma, bowling, Counter Strike, chest and spider.

\section{Conclusion}

Based on these results, the data reveals that students in the study do not spend much time in various literacy events to increase their literacy in English. The differences in the responses of boys and girls in the study reflect how the cultural interests of boys and girls in Brunei are gendered as early as primary schools. The qualitative analysis has revealed that girls were keen to participate in activities that increased their literacy skills such as drawing, using the computer and completing homework. Boys, on the other hand, preferred playing video games and participating in physical activities, and had less liking for homework activities. I recommend that further study to be conducted to confirm these results and trend among the students in Brunei and to gain further insights into the issues.

\section{References}

Arthur, J., \& Martin, P. W. (2006). Accomplishing lessons in postcolonial classrooms: Comparative perspectives from Botswana and Brunei Darussalam. Comparative Education, 42(2), 177-202. https://doi.org/10.1080/03050060600628009

Beardsmore, B. H. (1998). Implementation Proposals for Improved Bilingual Education, Ministry of Education, Negara Brunei Darussalam. (Report)

Barton, D., \& Hamilton, M. (2000). Literacy practices. In D. Barton, M. Hamilton \& Ivanic (Eds.), Situated literacies: reading and writing in context (pp. 7-15). London: Routledge.

Barton, D. (2007). Literacy: An Introduction to the Ecology of Written Language. 2nd edition. Oxford: Wiley-Blackwell.

Barton, D., \& Hamilton, M. (2000). Literacy practices. In D. Barton, M. Hamilton and Ivanic (Eds.), Situated literacies: reading and writing in context (pp. 7-15). London: Routledge.

Cummins, J. (1988). From Multicultural to Anti-Racist Education: An Analysis of Programmes and Policies in Ontario. In: Skutnabb-Kangas T., \& Cummins J (Eds.), Minority Education: From Shame to Struggle. Clevedon, UK: Multilingual Matters Ltd.

Datta, M. (2000). (Eds.) Bilinguality and Literacy: Principles and Practice. London New York: Continuum International Publishing Group Ltd.

Dhinsa, H. (2008). Cultural dimensions of the learning environment in Brunei. International Journal of Science and Mathematics Education, 6, 261-267. https://doi.org/10.1007/s10763-007-9077-8

Jones, G. M. (2003). Accepting Bilingualism as a Language Policy: An Unfolding Southeast Asian Story. In David C.S. Li. (2003) (Ed.), Bilingualism: Basic Principles, Clevedon: Multilingual Matters. https://doi.org/10.21832/9781853596315-010 


\section{Mll Macrothink}

International Journal of English Language Education

ISSN 2325-0887

2020, Vol. 8, No. 2

Jones, G. M. Martin, \& C. Ozog. (1993). Multilingualism and Bilingual Education in Brunei Darussalam. Journal of Multilingual and Multicultural Development, 14, (1 and 2), 39-58. https://doi.org/10.1080/01434632.1993.9994519

Jones, G. M., \& Ozog, A.C.K. (1993). Bilingualism and National Development. Clevedon: Multilingual Matters.

Jones, G. M. (1996). Bilingual education and syllabus design: Towards a Workable Blueprint. Journal of Multilingual and Multicultural Development, 17(2-4), 280-93. https://doi.org/10.1080/01434639608666281

Garcia, O. (2009). Bilingual education in the 21st century: A global perspective. England: Wiley- Blackwell.

Geertz, C. (1993). Thick Description: Toward an Interpretive Theory of Culture. In The Interpretation of Cultures: Selected Essays. New York: Basic Books, 3-30.

Ghadessy, M., \& Nicol, M. (2002). Attitude change in Bilingual education: The case of Brunei Darussalam. International Journal of Bilingual Education and Bilingualism, Vol. 5, No. 2. https://doi.org/10.1080/13670050208667750

Government of Brunei Darussalam. (1985). Education System of Negara Brunei Darussalam. Bandar Seri Begawan: Curriculum Development Centre, Ministry of Education.

Heath, S. B. (1982). Protean shapes in literacy events. In D. Tannen (Ed.), Spoken and written language: exploring orality and literacy (pp. 91-117). Norwood, N.J.: Ablex Publishing Company.

Kenner, C. (2003). An Interactive Pedagogy for Bilingual Children. In Bearne, E. Dombey, H. and Grainger, T. (eds.) Interactions in Language, Literacy and the Classroom. Milton Keynes: Open University Press.

Langer, J. (1987). A sociocognitive on literacy. In J. Langer (Ed.), Language, literacy and culture: Issues of society and schooling (pp. 1-20). Norwood, N.J.: Ablex Publishing Corporation.

Larking, L. (1996). Bilingualism through the classroom: Strategies and Practices in Brunei Darussalam.Journal of Multilingual and Multicultural Development. Vol. 17, No. 2 - 4, 296 311. https://doi.org/10.1080/01434639608666283

Larking, L., \& Ahmad, H. M. T. (1997a). Literacy in the Home and in the School in Brunei Darussalam. Studies in Education (No. 2, 1997).

Martin, P. W. (1996). Code - Switching in the Primary Classroom: One Response to the Planned and the Unplanned Language Environment in Brunei. Journal of Multilingual and Multicultural Development, 17(2-4), 128-44. https://doi.org/10.1080/01434639608666265

Martin, P. W. (1998). Bilingual classroom practices in the primary school: strategies for coping with a post-colonial legacy in Brunei. Journal of Multilingual and Multicultural Development, 128-144. 


\section{Macrothink}

Martin, P. W. (1999). Bilingual unpacking of monolingual texts in two primary classrooms in Brunei. Language and Education, 13(1), 38-58. https://doi.org/10.1080/09500789908666758

Martin, P. W. (2005). Talking knowledge into being in a primary school in Brunei. In A. S. Canagarajah (Ed.), Reclaiming the Local in Language Policy and Practice (pp. 225-246). Mahwah, N.J.: Lawrence Erlbaum Associates.

Purcell-Gates, V. (1996). Stories, coupons, and the 'TV Guide': relationships between home literacy experiences and emergent literacy knowledge. Reading Research Quarterly, 31(4), 406-428. https://doi.org/10.1598/RRQ.31.4.4

\section{Copyright Disclaimer}

Copyright for this article is retained by the author(s), with first publication rights granted to the journal.

This is an open-access article distributed under the terms and conditions of the Creative Commons Attribution license (http://creativecommons.org/licenses/by/3.0/). 